\title{
The properties of bimetallic multi-layer (C45 and S235JR) and the multi-layer steel made by forging
}

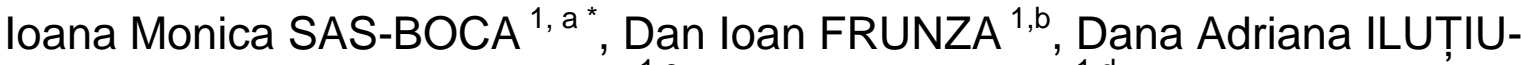 \\ VARVARA $^{1, c}$, and Istvan TOMA ${ }^{1, d}$ \\ ${ }^{1}$ Technical University of Cluj-Napoca, 28 Memorandumului Street, 400114, Cluj-Napoca, \\ Romania \\ amonica.sas.boca@ipm.utcluj.ro, bdan.frunza@ipm.utcluj.ro, \\ cdana.adriana.varvara@insta.utcluj.ro, doma_istvan@yahoo.com
}

Keywords: Multi-layer, Bimetallic material, Forging.

\begin{abstract}
In this paper are presented the results of the research on properties and behavior of hotforged bimetallic multi-layer material (C45-S235JR) compared to the properties and behavior of hot-forged multi-layer materials C45 and S235JR. The material was layered by successive manual hot forging to form 36-layers of the billets. Thus, it has been attempted to obtain superior materials in terms of properties, to withstand the demands they are subjected to. It has also been tried by stratification, obtaining results particularly relevant for resilience testing, where the different layer breakage occurs at higher strengths and has a high malleability. The microstructure of multi-layered materials was investigated in this paper and the mechanical properties were studied by tensile testing and Charpy impact testing. The Brinell micro-hardness has also been studied.
\end{abstract}

\section{Introduction}

Hot plastic deformation processes are the most common and used method for generating metallurgical metals [1, 2]. These processes are based on the characteristics of the metals obtained by high-temperature processing. By heating metals, we get less mechanical strength and increased malleability [3, 4]. Thus, raw materials can be processed with low material losses and low energy consumption in a form close to the finished piece.

The need to obtain the most effective and safe materials leads to a reorientation of the research to the ancient techniques [5] and technologies applicable to modern areas, such as cycling and, in particular, the acrobatics on the bicycle.

The main objective of the paper was to determine the characteristics [6 - 8] of the layered metal [9 - 11]. Another approach was to obtain bimetallic layered steel by forging [12]. This type of material combines the advantages of both materials and reduces the major inconvenience of each one taken separately. Often, the outer part of the piece is made of other metallic material to provide outstanding properties, as well as to reduce the cost price. This is possible due to the understanding of the function of the piece because the piece needs a certain mechanical strength $[4,13,14]$, which does not mean that the whole piece will be made of that material but only that part inner or the outer part of the piece. The rest of the material can be a cheaper material also, in accordance with the requirements of the finished product.

In this work was aimed at making multi-layered steel bars and sandwich bars (C45- S235JRC45).

The mechanical and microstructural properties were determined as follows: the tensile testings, Brinell hardness measurement, Charpy impact testing and microstructures were performed. 


\section{Material and method}

The materials used are the C45 band according to SR EN 10083 and the S235JR steel band according to EN 10204/2004. The chemical composition according to the current standards is presented in Table 1.

Table 1. Chemical composition

\begin{tabular}{|c|c|c|c|c|c|c|c|c|c|}
\cline { 2 - 9 } \multicolumn{1}{c|}{} & $\mathbf{C}$ & $\mathbf{M n}$ & $\mathbf{S i}$ & $\mathbf{P}$ & $\mathbf{S}$ & $\mathbf{C u}$ & $\mathbf{N i}$ & $\mathbf{N}$ & $\mathbf{C r}$ \\
\hline C45 & 0.45 & 0.7 & $\leq 0.30$ & $\leq 0.035$ & $\leq 0.4$ & & & & \\
\hline S235JR & 0.13 & 0.5 & 0.15 & 0.018 & 0.007 & 0.05 & 0.03 & 0.012 & 0.05 \\
\hline
\end{tabular}

The sandwich multi-layer resulted from manual hot forging. The billets were made of 36 layers.

The materials that we have been used in the study (not only C45 but even S235JR) were came from commercial source, laminate bar of 30x30x100. These were hot forged on the supporting bar which has a handling purpose. The heating at about $1100{ }^{\circ} \mathrm{C}$ has been done within a coal forge. After the heating process the sample has been immersed into borax and are-put into the forge. When the sample reached the $1100{ }^{\circ} \mathrm{C}$ again then it has been manually forged in order to achieve the welding between layers. The process has been about $3-4$ times repeated until it has been accomplished a product which has not any fissures; after that the material has been stretched and bent in order to obtain the 12 layers.

The bent processes and the forges for the C45 multi-layer samples and for the S235JR multilayer samples have been another 2 times repeated in order to obtain some bars semi-finished products which have a square section of 36 layers. In order to achieve the sandwich shape product there have been together forged about 24 of C45 layers which have in the middle of them about 12 layers of S235JR which have been accomplished in the same way.

The material has been stretched through free forging process and cut into bars of 100mm length each; from these bars there have been done some specimens for traction, resilience and hardness tests. The multi-layers samples which belong to the same semi-finished product has been labeled with 1,2,3 numbers as: multi-layer C45_1, multi-layer C45_2, multi-layer C45_3 for the specimens obtained from the C45 multi-layer; multi-layer S235JR 1, multi-layer S235JR 2, multilayer S235JR 3 for the specimens obtained from the S235JR multi-layer and sandwich 1, sandwich 2, sandwich 3 for the specimens obtained from the 24 layers of C45 which have in the middle 12 layers of S236JR.

By bending, twelve-layer billets of the same material were made. In the final stage, three types of billets were made by layer overlays, such as 36-layer C45 steel specimen, 36-layer S235JR steel specimen and sandwich specimen 12 x C45 - 12 x S235JR - 12 times x C45.

The borax was used to clean the oxides on the three sandwich packages, ensuring better bonding of the layers.

The strength and tensile ductility, toughness, and brittle-to-ductile transition have been the main thrust for multi-layer investigations. The tensile testings were performed on a $200 \mathrm{kN}$ Heckert-EDZ-20S testing machine. Brinell hardness measurement was performed with a Amsler OTTO Wolpert-WERKE GMBA Hardness Tester Typ. Dia Testor 2 Rc-S type with $\emptyset 5$ mm ball, the ductility were determinated using a 300N. Instrumented Charpy impact tests were performed 
according to the standard ASTM A370 on impact testing machine, the microstructures were performed using a Jenoptik Prog Res C10 photodigital microscope.

\section{Results and test methods}

The Charpy test specimens (Fig. 1a) of dimensions 10x10 mm with a length of $55 \mathrm{~mm}$ and a Unotch with a radius of $1 \mathrm{~mm}$ were made from billets. It can be noticed that the outer layers of carbon with higher carbon content (C45) have cracked and the inner layers are only strongly deformed (plastic deformation) (Fig. 1b).

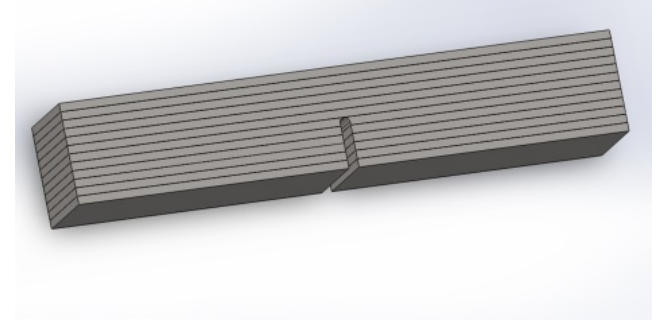

a) Initial samples of resilience

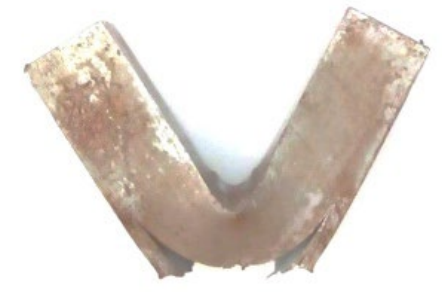

c) The stratified S235JR material

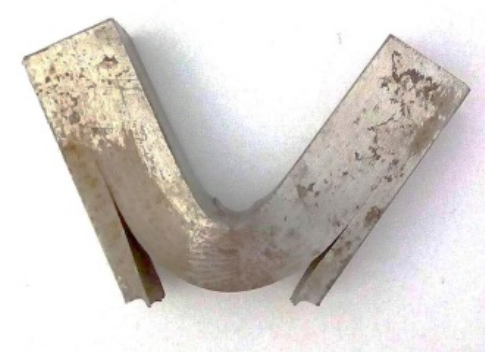

b) The stratified C45 material

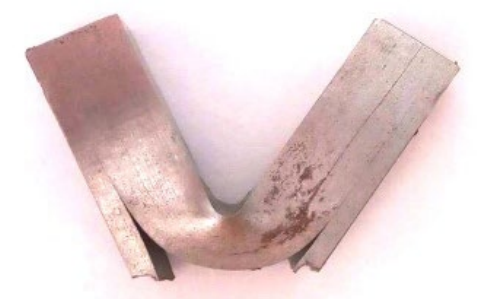

d) Sandwich material (C45 + S235JR +C45)

Fig. 1. Charpy impact test samples.

The obtained results (Fig. 2) of the impact tests are superior for the sandwich material (Fig. 1d) versus S235JR multi-layer material (Fig. 1c) or the C45 multi-layer material (Fig. 1a). Thus, assumptions were made that the tougher exterior of the sample (C45) and the softer interior (S235JR) represent a malleability characteristic that requires more energy compared to the single type of layered material (S235JR or C45).

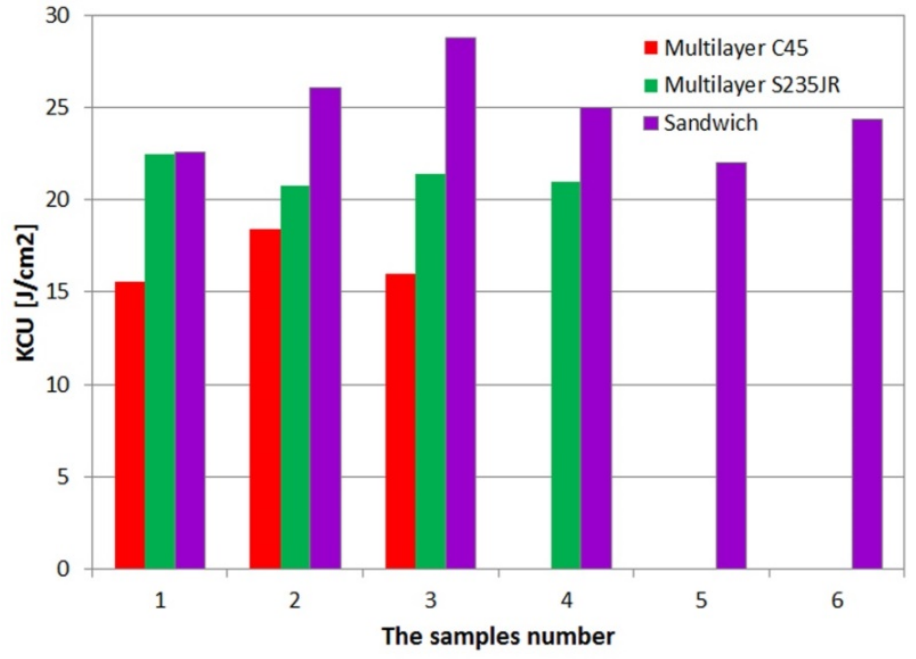

Fig. 2. Charpy impact test results. 
When assessing the tenacity of a material, the macroscopic appearance of the breakage section must also be taken into account. This aspect generally has two distinct parts: an outer part with a crystalline, fibrous and matte appearance, corresponding to a fragile crack, and the other central part, grunt and shiny, corresponding to a plastic deformation (breaking tenacity).

It can be seen from Fig. 2, for sandwich models (magenta) the resilience was obtained by 15,7\% higher than for S235JR steel specimens (green) and also by 49,3\% higher than for specimens of C45 with 36 layers (red).

From Figure 3 can be observed that sandwich specimens have an intermediate hardness between C45 multi-layer steel and S235JR multi-layer steel and have a better uniformity in results than the other samples, from $183 \mathrm{HB}$ to $197 \mathrm{HB}$.

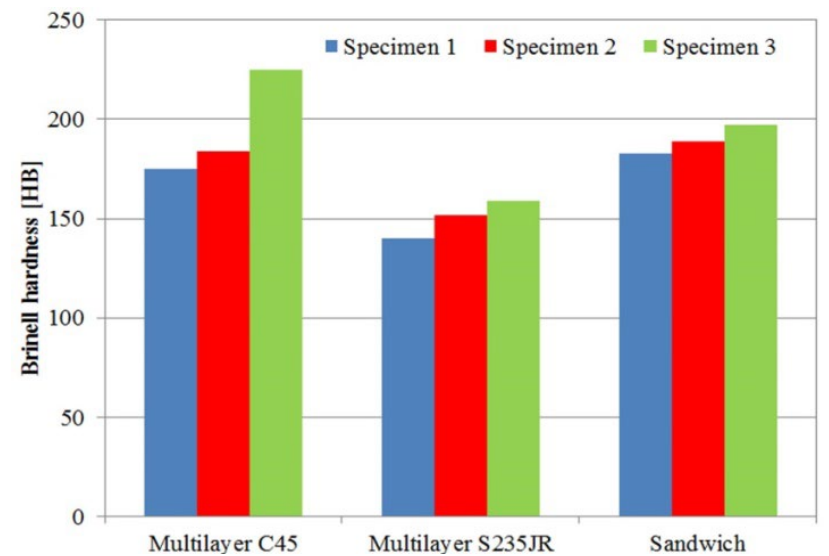

Fig. 3. Brinell hardness test.
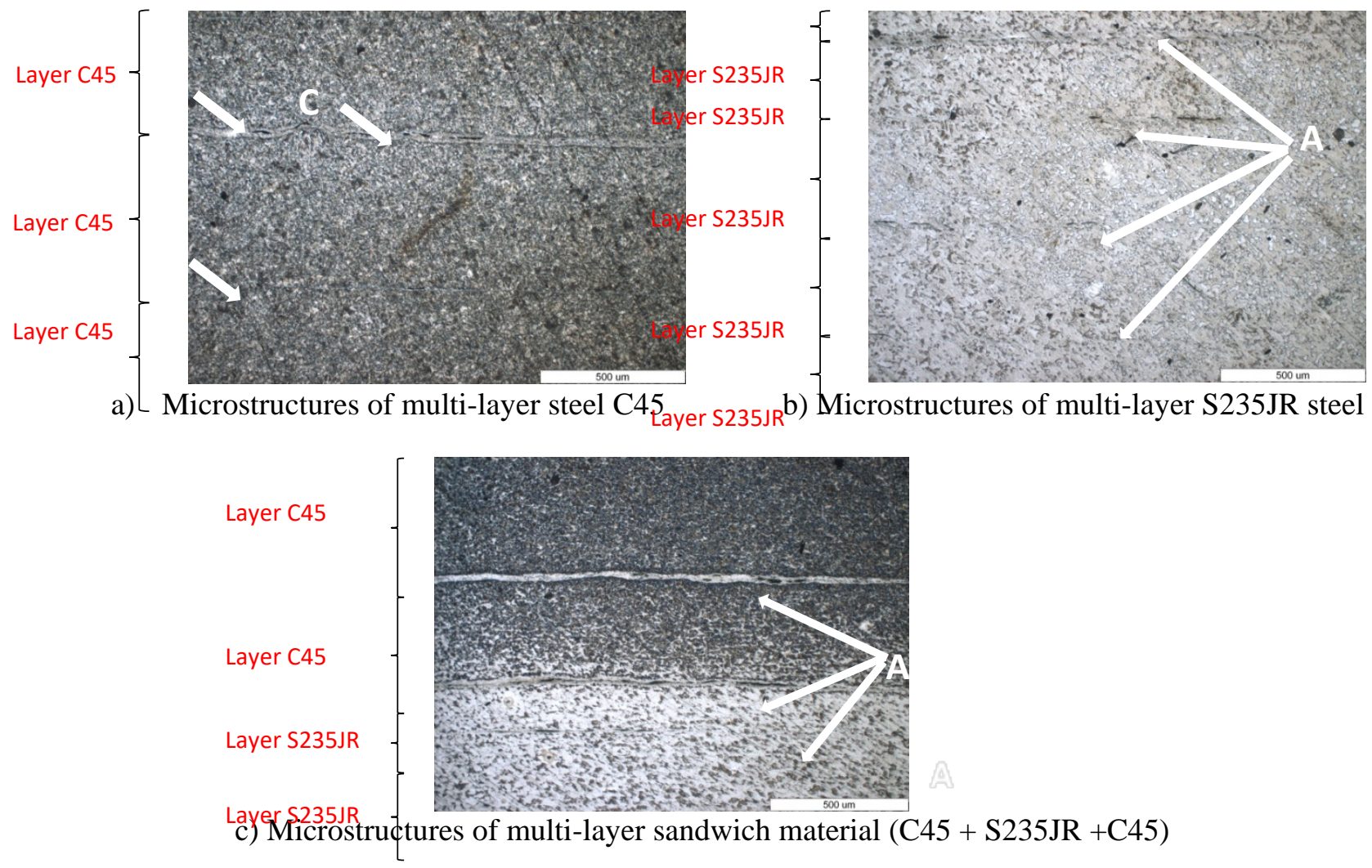

Fig. 4. The microstructures of the samples 100x. 
The forged specimens had a smooth and homogeneous structure, but due to many forging defects, such as decarburization, inclusions and complete welding failure, the results were not as homogeneous as we expected.

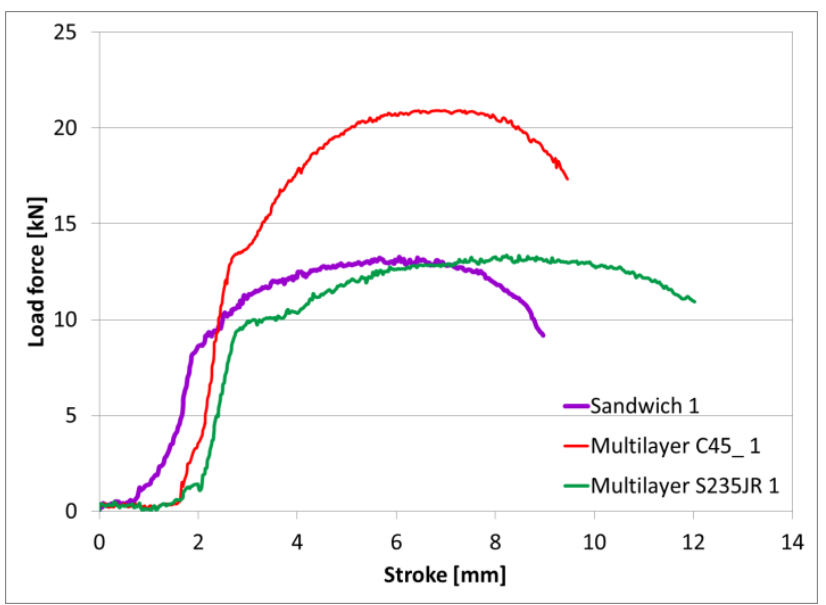

a) Specimen 1

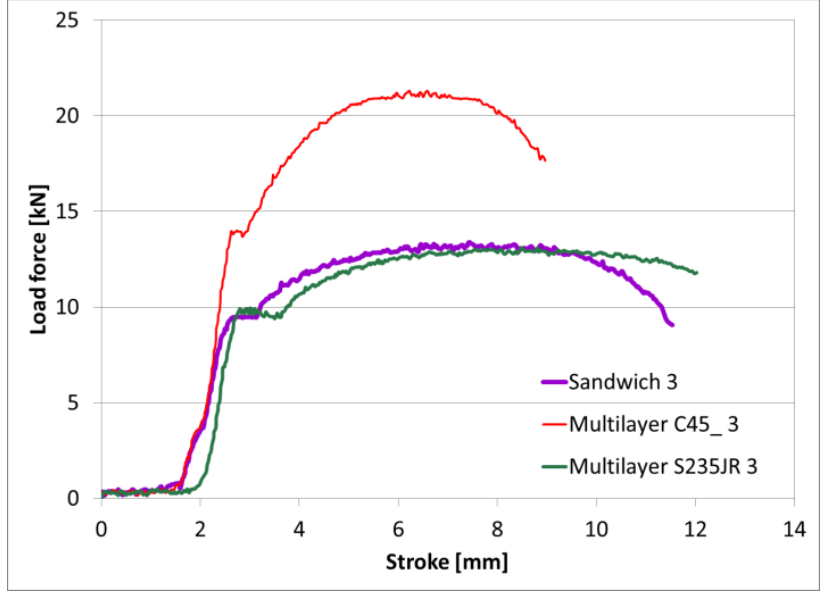

c) Specimen 3

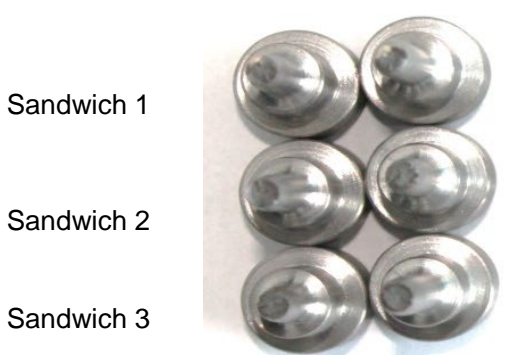

b) Sandwich
S235JR 1

S235JR 2

S235JR 3

c) Multi-layer S235JR

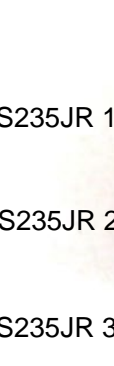

Fig. 5. Tensile test.

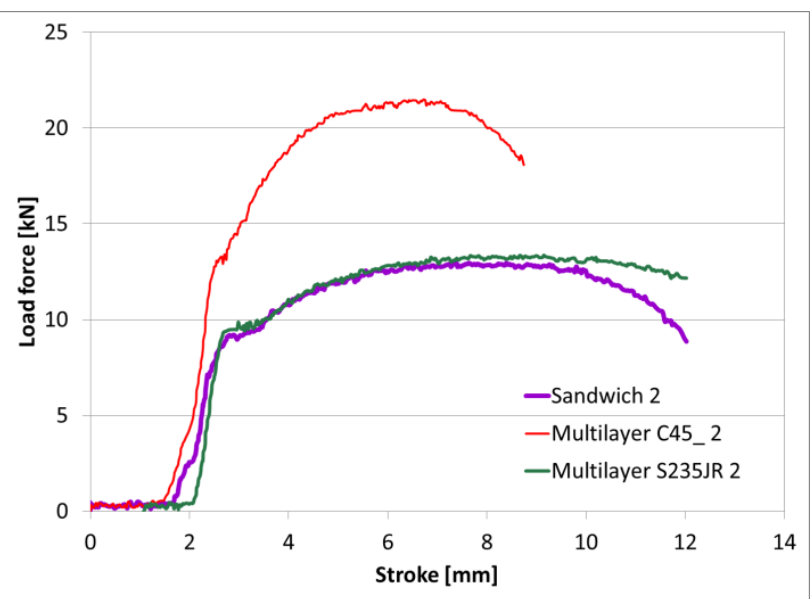

a) Specimen 2

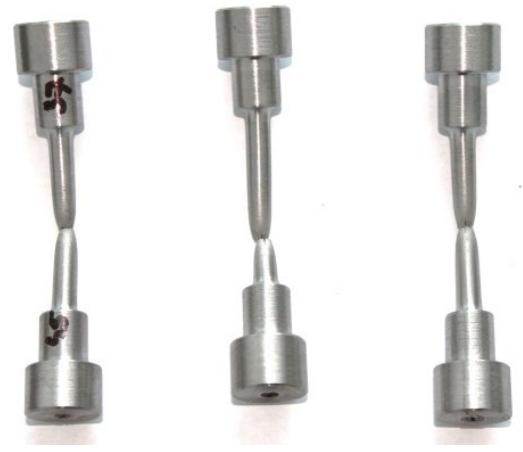

d) Specimen of sandwich tensile test

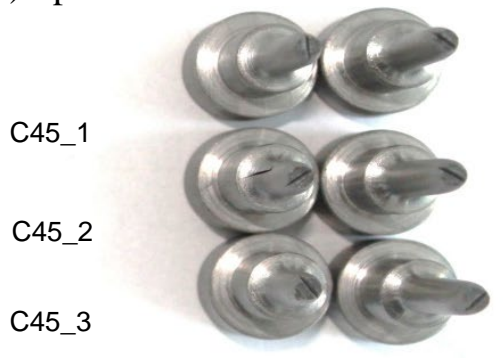

d) Multi-layer C45

The impact test specimen needed an identification of position on the steel layers to perform resilience tests correctly and uniformly on all samples. Was prepared and studied the specimens to be observed under a metallographic microscope, the attack was performed with nital. 
The specimens were study by optical microscopy (Fig. 4), the layers were observed and analyzed. The boundaries between the layers it was searched, so was managed to identify the overlapping planes.

The ferrite-pearlite structure is dominating. The microstructures show the interface (A) between layers shows discontinuities and, in their proximity,, a slight decarburization (C) can be observed in the C45 steel layer below 50 micrometers. At the same time, in the case of this sample, it can be seen that in the C45 steel area at the bending interface (B) the presence of an excess of borax about 10 micrometers thick is observed.

For sandwich samples: (Fig. 5) it can be seen that the force $(14 \mathrm{kN})$ determined in the tensile testing is close to that of the S235JR steel samples. At tensile testing, all the sandwich samples had a ductile behavior. The sandwich specimens behaved like a medium ductility with ductile fracture type, which showed the separation of the forged layers in some cases.

The C45 specimens (multi-layer C45_1,2, 3) had superior S235JR (multi-layer S235JR 1,2,3) characteristics with a shorter neck and force required to achieve higher fracture. The rupture is of the ductile fracture type and does not reveal the detachment of the forged layers. It can be seen in Figure 5 that sandwich 1,2,3 specimens show shorter cracks than the S235JR steel specimens, but the maximum forces are similar.

\section{Summary}

From the Charpy impact test results, it can be concluded that the sandwich material has superior characteristics, is more ductile than C45 multi-layer material. The C45 material steel layers (from sandwich) are more fragile and cracks, also and for the S235JR steel layers (from sandwich) have high ductility, so they deform and absorb more energy but do not fracture (it is there a plastic deformation without cracks deflection). The fact that the $\mathrm{C} 45$ steel layers are broken is a technological advantage. From the point of view of requesting a bicycle frame made of the bimetallic multi-layer material (sandwich), when at the exterior we have strongest layers from more fragile material (multi-layer C45) and the inner ductile (S235JR multi-layer) exhibits a higer malleability (about 15.3\% to specimens S235JR multi-layer, and about 49,3\% to specimens C45 multi-layer). So that may be a warning to the user and it can avoid serious injuries caused by its totally break-down.

The hardness analysis has revealed that the exterior layers of the sandwich, C45 multi-layer ones are harder and give better resistance. The sandwich specimens have an intermediate hardness between C45 multi-layer steel and S235JR multi-layer steel and have a better uniformity in results than the other samples, from $183 \mathrm{HB}$ to $197 \mathrm{HB}$.

The optical microstructures have helped to properly study the bounding of the layers and samples.

It can be clearly noticed (Fig. 1) that the brittle-to-ductile transition of the C45 multi-layer from outside to the S235JR multi-layer inside.

It can also be concluded that the other two layered materials show similarities in the test stress. A future research could be comparing the results obtained from testing C45 and S235JR with the layered materials of the same materials.

\section{References}

[1] H. Berns, The history of hardening, Harterei Gerster AG, 2013.

[2] R. L. Apps, D. R. Milner, Introduction to welding and brazing, Pergamon Press, 1994.

[3] K. C. John, Metal casting and joining, PHI Learning, 2015. 
[4] ***ASM Handbook Volume 8: Mechanical testing and evaluation, ASM International, 2000.

[5] T. Fumon, Samurai fighting arts: the spirit and the practice. Kodansha International, 2003.

[6] G.E. Dieter, Introduction to ductility, in Ductility, American Society for Metals, 1968.

[7] ***ASM Handbook Volume 9: Metallography and microstructures, ASM International, 2004.

[8] *** ASM Handbook Volume 14: Forming and forging, ASM International, 1998.

[9] J. Reisera, L. Garrisonb, H. Greunerc, J. Hoffmanna, T. Weingärtnera, U. Jäntscha, M. Klimenkova, P. Frankea, S. Bonka, C. Bonnekoha, S. Sickingera, S. Baumgärtnera, Daniel Bolicha, M. Hoffmanna, R. Zieglera, J. Konrada, J. Hohed, A. Hoffmanne, T. Mrotzeke, M. Seisse, M.l Rietha, A. Möslanga: Ductilisation of tungsten (W): Tungsten laminated composites, Int. J Refractory Metals Hard Mater. 69 (2017) 66-109.

[10] Y. Zhang, T. Ouyang, D. Liu, Y. Wang, J. Du, C. Zhang, S. Feng, J. Suo: Effect of thickness ratio on toughening mechanisms of Ta/W multi-layers, J All. Compd. 666 (2016) 30-37. https://doi.org/10.1016/j.jallcom.2016.01.084

[11]Y. Zhang, G. Xu, Y. Wang, C. Zhang, S. Feng, J. Suo: Mechanical properties study of W/TiN/Ta system multi-layers, J All. Compd. $725 \quad$ (2017) 283-290. https://doi.org/10.1016/j.jallcom.2017.07.115

[12] N. A. Mara, I. J. Beyerlein: Interface-dominant multi-layers fabricated by severe plastic deformation: stability under extreme conditions, Curr. Opin. Solid State Mater. Sci. 19 (2015) 265-276. https://doi.org/10.1016/j.cossms.2015.04.002

[13] X.P. Zhang, S. Castagne, T.H. Yang, C.F. Gu, J.T. Wang: Entrance analysis of 7075 Al/MgGd-Y-Zr/7075 Al laminated composite prepared by hot rolling and its mechanical properties, Mater. Des. 32 (2011) 1152-1158. https://doi.org/10.1016/j.matdes.2010.10.030

[14] G. Annea, M.R. Ramesha, H. S. Nayakaa, S. B. Arya: Investigation of microstructure and mechanical properties of $\mathrm{Mg}-\mathrm{Zn} / \mathrm{Al}$ multi-layered composite developed by accumulative roll bonding, Perspectives in Science 8 (2016) 104-106. https://doi.org/10.1016/j.pisc.2016.04.008 